Western University Scholarship@Western

$7-2017$

\title{
Maternal Undernutrition and Long-term Effects on Hepatic Function
}

Daniel B. Hardy

Physiology and Pharmacology, daniel.hardy@schulich.uwo.ca

Follow this and additional works at: https://ir.lib.uwo.ca/physpharmpub

Part of the Medical Physiology Commons, Pharmacy and Pharmaceutical Sciences Commons, and the Reproductive and Urinary Physiology Commons

Citation of this paper:

Hardy, Daniel B., "Maternal Undernutrition and Long-term Effects on Hepatic Function" (2017). Physiology and Pharmacology Publications. 99.

https://ir.lib.uwo.ca/physpharmpub/99 


\section{Author's Proof}

\section{Chapter 9 \\ Maternal Undernutrition and Long-Term Effects on Hepatic Function}

\section{Key Points}

- This chapter focuses on human and animal data linking undernutrition in utero (i.e., placental insufficiency, nutrient restriction, maternal low protein) with long-term hepatic dysfunction in postnatal life.

- Undernutrition in utero influences lipid homeostasis, gluconeogenesis, insulin sensitivity, drug metabolism, and overall growth leading to liver fibrosis and long-term symptoms of the metabolic syndrome.

- Some of the direct mechanisms linking undernutrition in perinatal life to hepatic dysfunction include hypoxia and epigenetic influences (i.e., DNA methylation, posttranslational histone modifications, and microRNAs).

- Rapid postnatal catch-up growth can indirectly augment hepatic ER stress leading to impaired insulin signaling and alterations in microRNAs in the liver.

- Animal studies have indicated that intervention in perinatal life with essential nutrients, hormones, or modulators of nuclear receptors can rescue hepatic gene expression and may prevent the longterm metabolic deficits associated with the undernourished liver.

Keywords $\mathrm{DOHaD} \bullet$ Epigenetics $\bullet$ Maternal low-protein diet $\bullet$ Hypoxia $\bullet$ Uterine ligation $\bullet$ Nuclear 5 receptors $\bullet$ Posttranslational histone modifications $\bullet$ DNA methylation $\bullet$ Endoplasmic reticulum stress 6

- MicroRNAs

\section{Abbreviations}

Supported by: CIHR Operating Grant and Natural Sciences and Engineering Research Council of Canada.

D.B. Hardy $(\bowtie)$

The Departments of Obstetrics \& Gynecology and Physiology \& Pharmacology, The Children's Health Research Institute and the Lawson Health Research Institute, The University of Western Ontario, London, ON, Canada e-mail: Daniel.Hardy@schulich.uwo.ca 


\section{Author's Proof}

$\begin{array}{lll}12 & \text { CpG } & \text { Cysteine-phosphate-guanine } \\ 13 & \text { CVD } & \text { Cardiovascular disease } \\ 14 & \text { Cyp2c11 } & \text { Cytochrome P450 2c11 } \\ 15 & \text { Cyp3a1 } & \text { Cytochrome P450 3a1 } \\ 16 & \text { Cyp7a1 } & \text { Cytochrome P450 7a1 } \\ 17 & \text { EPO } & \text { Erythropoietin } \\ 18 & \text { ER stress } & \text { Endoplasmic reticulum stress } \\ 19 & \text { EX-4 } & \text { Exendin-4 } \\ 20 & \text { G6Pase } & \text { Glucose-6 phosphatase } \\ 21 & \text { GLP-1 } & \text { Glucagon-like peptide-1 } \\ 22 & \text { GR } & \text { Glucocorticoid receptor } \\ 23 & \text { HDL } & \text { High-density lipoproteins } \\ 24 & \text { IGF-1 } & \text { Insulin growth factor 1 } \\ 25 & \text { IUGR } & \text { Intrauterine growth restriction } \\ 26 & \text { JMJD } & \text { Jmj domain-containing histone demethylation protein } \\ 27 & \text { LDL } & \text { Low-density lipoproteins } \\ 28 & \text { LP } & \text { Low protein } \\ 29 & \text { LXR } & \text { Liver X receptor } \\ 30 & \text { miRs } & \text { MicroRNAs } \\ 31 & \text { MMP2 } & \text { Matrix metalloproteinase 2 } \\ 32 & \text { MNR } & \text { Maternal nutrition restriction } \\ 33 & \text { MPR } & \text { Maternal protein restriction } \\ 34 & \text { pAkt1 (Ser473) } & \text { Phospho Akt1 (serine 473) } \\ 35 & \text { Pck1 } & \text { Phosphoenolpyruvate carboxykinase 1 (soluble) } \\ 36 & \text { pEIF2 } \alpha & \text { Phospho-eukaryotic translation initiation factor 2 } \\ 37 & \text { PND } & \text { Postnatal day } \\ 38 & \text { PPAR } & \text { Peroxisome proliferator-activated receptor } \\ 39 & \text { SGA } & \text { Small for gestational age } \\ 40 & \text { SMAD4 } & \text { SMAD family member 4 } \\ 41 & \text { TGFB1 } & \text { Transforming growth factor } \beta 1 \\ 42 & \text { TUDCA } & \text { Tauroursodeoxycholic acid } \\ 43 & \text { UPR } & \text { Unfolded protein response } \\ 44 & \text { VEGF } & \text { Vascular endothelial growth factor } \\ & & \\ & & \\ 32 & \end{array}$

The liver plays a critical role in mammals for metabolism, digestion, detoxification, storage, protein production, and immunity. Given the role of the liver in cholesterol, fatty acid, and glucose homeostasis, it is not surprising hepatic dysfunction underlies several of the symptoms (i.e., hypercholesterolemia, obesity, glucose intolerance) characterizing the metabolic syndrome [1,2]. The surge in the incidence of the metabolic syndrome worldwide is of great concern considering that it raises the risk of developing cardiovascular disease (CVD) by 20-fold, and CVD is responsible for 1 out 2.9 deaths in the United States [3-6]. In addition to the metabolic syndrome, impaired liver health and function also can lead to liver fibrosis (and the end-stage cirrhosis), which is estimated to contribute up to $45 \%$ of deaths in the developed world [7,8]. Liver fibrosis is a major predictor for diabetes, overall liver failure, portal hypertension, and liver cancer [9-11]. Since diet (i.e., "Western diet") is a major contributor to defects in liver function and ultimately liver fibrosis or CVD, current therapeutic strategies are aimed at lifestyle modifications (i.e., physical activity and healthy eating) and/or pharmaceutical interventions to treat the disease once manifested [12-15]. While pharmaceuticals may be effective 


\section{Author's Proof}

9 Maternal Undernutrition and Long-Term Effects on Hepatic Function

reducing the risk of CVD, the long-term dependency on them can be dangerous for the liver. For example, statins can reduce the risk of ischemic heart disease by up to $60 \%$; however, the existence of statin-induced rhabdomyolysis and hepatitis-associated liver failure emerges in some patients [16]. Clearly additional studies are warranted for hepatic disease prevention versus treatment. A major preventative strategy is in recognizing the early origins of adult disease so that efficacious interventions can be targeted to prevent long-term defects in liver function.

\section{Maternal Undernutrition and Impaired Hepatic Function: Clinical Evidence}

Over 25 years ago, Professor David Barker revealed that adverse in utero events can permanently alter physiological processes leading to the metabolic syndrome [17]. The early evidence that an impairment of liver size and/or function was involved came from the fact that there was a strong correlation between reduced abdominal circumference at birth with elevated total and LDL cholesterol in adulthood [18]. Secondly, intrauterine growth restriction (IUGR), caused by either placental insufficiency or maternal malnutrition, often results in asymmetric organ development whereby there is a reduction in the growth of less essential organs such as the liver, lungs, and kidneys [19, 20]. Thirdly, there is a strong inverse relationship between birth weight and obesity or glucose intolerance; both under the regulation of the liver [21-24]. It is noteworthy that the majority of these links to metabolic disease arose from large population-based studies whereby under nutrition in utero (i.e., due to famine) was the major factor leading to impaired fetal growth [21, 25-28].

Postpartum, the major factor influencing this inverse relationship between low birth weight and metabolic disease is nutrition-induced accelerated growth in neonatal life, which leads to an earlier onset of the symptoms of the metabolic syndrome [25, 29-31]. Barker explained this phenomenon with the "predictive adaptive response" hypothesis, which suggests that "adverse events during development induce adaptations suited for survival in a similar predictive environment but can become maladaptive if a mismatch to the predictive environment occurs, leading to a thrifty phenotype" $[32,33]$. Since IUGR leads to major decreases in fetal liver development, it seems conceivable that the liver has the most to gain in growth during postnatal life $[19,20]$. Animal models of IUGR support that the undernourished liver undergoes rapid postnatal catch-up growth leading to further metabolic dysfunction, but there is evidence from human studies as well [34-36]. For example, infants born small for gestational age (SGA) undergo hypersomatotropism as early as 4 days as a result of increased circulating insulin growth factor 1 (IGF-1) produced by the liver [37]. Elegant studies by Singhal et al. have also demonstrated that low birth weight infants with rapid postnatal growth (due to growth-promoting formula diets) exhibited a higher LDL/HDL ratio, likely derived from impaired cholesterol homeostasis in the liver [38]. While future noninvasive imaging studies are warranted to tract liver development (i.e., liver growth, lipid composition) in IUGR infants long-term, animal models of maternal undernutrition have shed great light into the mechanisms underlying the fetal programming of the liver. More importantly, by elucidating some of the underlying mechanisms involved, new pharmaceutical and dietary intervention strategies can be employed to prevent these defects in liver function.

\section{Uterine Ligation or Ablation Model of Undernutrition and Long-Term Hepatic Function}

As previously mentioned, IUGR can occur due to placental insufficiency which occurs in about $8 \%$ of pregnancies [39, 40]. Animal studies have demonstrated that placental insufficiency-induced IUGR leads to decreases in oxygenation and substrate availability for the fetus [41-43]. Therefore, the uterine ligation or uterine ablation serves as an excellent model for examining idiopathic IUGR and the .

1




\section{Author's Proof}

short- and long-term effects on liver function. Both models lead to decreased birth weight and lower liver to body weight ratios $[35,44]$. In the guinea pig, uterine ablation led to a greater incidence of hepatic perisinusoidal or periportal fibrosis in 5-month offspring with increased expression of profibrogenic markers including TGF $\beta 1$, MMP2, and SMAD4 [44]. In rats, uterine ligation leads to development of the metabolic syndrome in the offspring including type 2 diabetes, dyslipidemia, and hypertriglyceridemia [45-47]. Interestingly, many of these symptoms were reciprocated into the F2 generation [48]. These metabolic deficits exist, in part, due to altered glucose transporter expression, impairment of fatty acid metabolism, increased glucocorticoid activity, augmented glucose production, and blunted insulin suppression all within the liver [45, 47, 49-51]. These offspring also exhibited decreased hepatic and circulating insulin growth factor 1 (Igf-1) which is critical for insulin function, glucose metabolism, and growth [52]. While other models of maternal dietary-induced IUGR led to hypercholesterolemia in postnatal life, uterine ligation appears to have no effect on cholesterol homeostasis unless the offspring were challenged with a high-fat diet in postnatal life [34, 53, 54]. Although this animal model is physiologically relevant to idiopathic IUGR, it is distinct from dietary-induced undernutrition as it leads to direct decreases in both oxygen and nutrients to the fetus. Other exclusive dietary models are essential in understanding the contribution of maternal malnutrition alone on long-term hepatic function and disease.

\section{Maternal Nutrient Restriction (MNR) Model of Undernutrition}

Human and animal studies of food restriction during pregnancy confirm that maternal undernourishment leads to IUGR depending upon the timing (pre- vs postconception) and severity of the insult [28, 29, 55-57]. Moreover, like models of uterine ligation, fetal liver growth from MNR dams is compromised at birth followed by rapid postnatal catch-up growth $[36,55,58]$. However, with models of MNR, the impact of a decrease in maternal and placental weight during pregnancy must also be taken into consideration $[55,59]$. Sheep and rat studies have demonstrated that MNR leads to glucose intolerance and insulin insensitivity, along with greater hepatic lipid and glycogen content in the offspring $[58,60]$. The impaired glucose tolerance in MNR sheep offspring is attributed, in part, to increased circulating cortisol and augmented hepatic PEPCK expression in MNR offspring [60]. In contrast to offspring of uterine ligation, MNR offspring with catch-up growth exhibited increases in Igf- 1 which the authors attribute is associated with decreased longevity, but not necessarily metabolic disease [58].

\section{Maternal Protein Restriction (MPR) Model of Undernutrition}

Placental insufficiency in humans often leads to protein (and amino acid) deficiencies in the fetus, which are critical for fetal growth [61, 62]. Therefore, the MPR model is a relevant model to study placental insufficiency-IUGR as it leads to asymmetric IUGR, without any effects on maternal weight gain or food intake [22, 63]. Moreover, MPR offspring have decreases in fetal liver weight at birth and, depending on the timing of protein restoration, display liver and whole body catch-up growth despite no differences in food intake [34, 64]. Remarkably, MPR offspring, more predominantly in males, exhibit several symptoms of the metabolic syndrome including glucose intolerance, visceral obesity, hypercholesterolemia, and hypertension [34, 65-69]. The glucose intolerance is attributed to augmented gluconeogenesis (e.g., G6Pase, 11 $\beta$-HSD1), diminished glucokinase expression, decreased pAkt1 (Ser473), and decreased glucagon receptor in the livers of MPR offspring [64, 67, 70, 71]. With respect to lipids, MPR male offspring with catch-up growth show increases in circulating hepatic cholesterol due to decreases in the expression of Cyp7a1, the critical enzyme in cholesterol metabolism [34]. Aside from alterations in glucose and cholesterol homeostasis, MPR male offspring with catch-up also 


\section{Author's Proof}

9 Maternal Undernutrition and Long-Term Effects on Hepatic Function

exhibit increases in hepatic Сyp3a and Cyp2c11 expression and activity influencing long-term drug metabolism (i.e., statins) in these offspring [72]. As testosterone is a major substrate for these Cyp enzymes, it may explain why MPR male offspring have lower circulating testosterone levels, and consequentially, the long-term sexual dimorphism which exists in this model [68]. Similar to uterine-ligated offspring, MPR offspring with catch-up growth have decreases in hepatic Igf-1; however, the decrease in Igf-1 is mainly attributed to the effects of protein restriction during lactation [63]. All in all, the MPR model truly reinforces the main principle of Barker's "predictive adaptive response" given that when there is no nutritional mismatch in postnatal life, MPR offspring do not exhibit any decreases in cholesterol catabolism, insulin sensitivity, or drug metabolism in the liver [34, 64, 72].

\section{Direct Mechanisms Linking Maternal Undernutrition and Adverse Metabolic Outcomes}

While human and animal studies have certainly established the strong links between an undernourished in utero environment and metabolic deficits in the offspring, we only just beginning to unravel the direct and indirect molecular events involved. Interestingly, one of the major direct drivers of altered hepatic gene expression and function short- and long-term would be hypoxia. While it is not surprising that uterine ligation directly leads to hypoxia in the liver, maternal undernutrition alone in guinea pigs also led to increases in the expression of markers of hypoxia (EPO, EPO receptor, VEGF) in the fetal liver and kidney [35, 73]. In uterine ligation studies, decreases in oxygenation reduced hepatic mitochondrial oxidative phosphorylation and further led to oxidative stress in young rat offspring $[35,47]$. Collectively, this explains the increased hepatic gluconeogenesis and impaired insulin signaling exhibited in this young offspring.

Epigenetic forces have also been implicated to play a direct and sustaining role in the fetal programming of the liver. Epigenetic mechanisms, which include direct DNA methylation, posttranslational histone modifications, and microRNAs (miRs), influence the long-term expression of a gene by altering the ability of the transcriptional machinery to interact with the chromatin environment. Elegant studies in the baboon fetus have demonstrated that $70 \%$ undernutrition during pregnancy led to augmented hepatic gluconeogenesis associated with both increased Pck1 mRNA and decreases in the methylation of $\mathrm{CpG}$ dinucleotides of the Pckl promoter [59]. Moreover, uterine ligation has been shown to directly increase DNA methylation in the promoter of hepatic Igf- 1 at birth and that this persists into the F2 generation even when F1 IUGR offspring are adequately nourished [48, 74]. Interestingly, in this study, supplementation of the diet in the F1 IUGR offspring with folic acid, choline, betaine, vitamin $\mathrm{B}_{12}$, and other essential nutrients prevented the methylation of the $I g f-1$ promoter in the F2 generation along with symptoms of the metabolic syndrome [48]. However, caution is necessary in the overall interpretation of these studies given undernutrition-induced alterations in DNA methylation can vary between sexes and within different $\mathrm{CpG}$ islands of the same promoter [74].

Posttranslational histone modifications, which include methylation, acetylation, phosphorylation, ubiquitination, and ADP-ribosylation of histones, serve as another epigenetic mechanism to influence long-term gene expression by perinatal undernutrition. This is evident when maternal dietary protein is restricted during pregnancy and lactation leading to long-term hypercholesterolemia as a result of decreased expression of hepatic Cyp7a1, the critical enzyme involved in cholesterol catabolism [34]. Remarkably, the histone modifications involved in MPR-induced silencing the expression of Cyp $7 a 1$ promoter, namely, increased trimethylation and decreased acetylation of histone $\mathrm{H} 3$ [lysine 9, 14], are sustained from 3 weeks to 4 months in postnatal life [34]. The origin of these histone modifications is due, in part, to MPR-mediated decreased in Jmjd2a and Jmjd2c, demethylases involved in removing trimethyl groups of histone H3 [lysine 9]. It is noteworthy that while both male and female MPR offspring exhibited decreased Cyp7a1 expression at 3 weeks, female MPR offspring at 4 months are protected from the posttranslational histone modifications silencing the Cyp $7 a 1$ promoter. MPR has 


\section{Author's Proof}

D.B. Hardy

also been demonstrated to lead to long-term posttranslational histone modifications (e.g., decreased histone $\mathrm{H} 3$ acetylation [lysine 9, 14] silencing the expression of the hepatic liver X receptor (LXR $\alpha)$ at 4 months (Fig. 9.1) [67]. The decrease in the expression of this repressive glucose sensor permitted

a

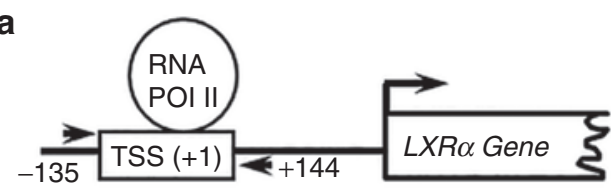

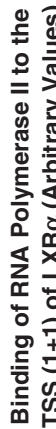

C

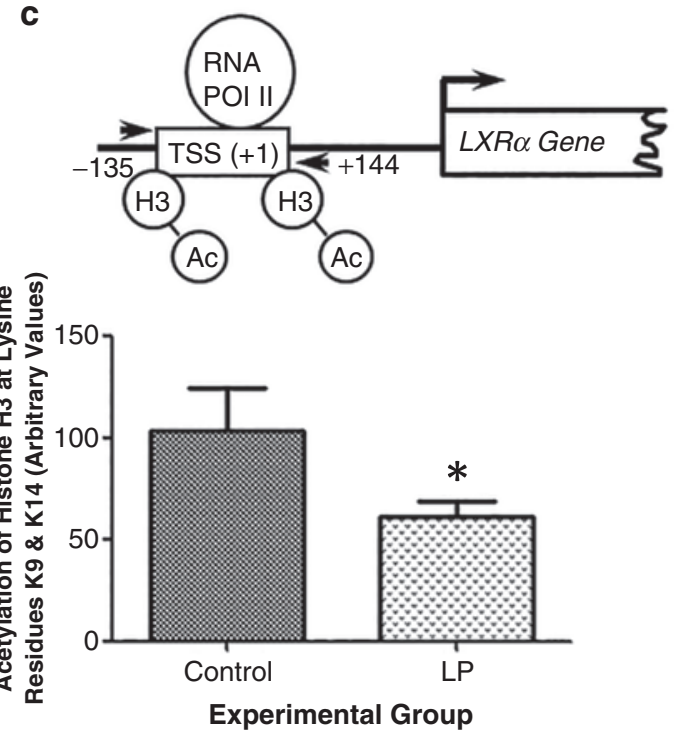

b

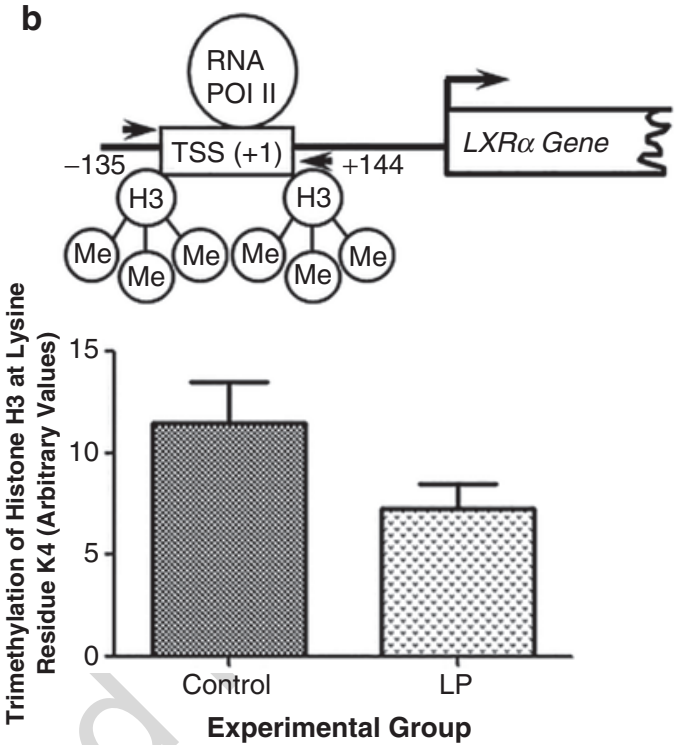

d

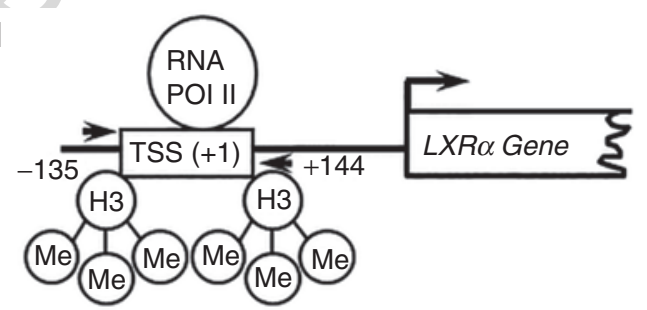

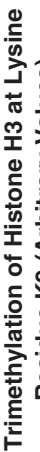

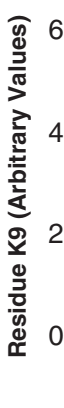

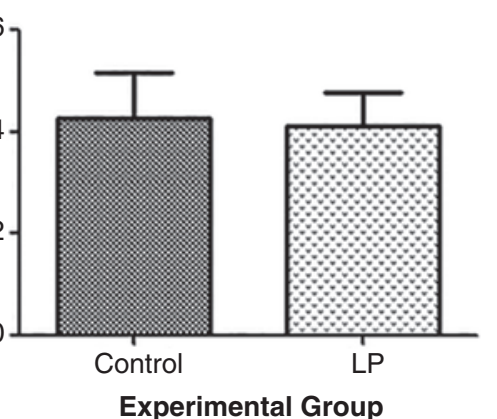

Fig. 9.1 The effect of maternal low-protein diet in utero on the in vivo transcriptional and epigenetic regulation of the LXR $\alpha$ transcriptional start site ( -135 to $+144 \mathrm{bp}$ ) at 4 months of age. (a) Binding of RNA polymerase II to the LXR $\alpha$ TSS, (b) trimethylation of histone $\mathrm{H} 3$ lysine 4, (c) acetylation of histone $\mathrm{H} 3$ lysine 9 and 14, and (d) trimethylation of histone H3 lysine 9. Primers were designed based on sequencing from Ensembl. Livers were immunoprecipitated with antibodies specific to RNA polymerase II, trimethylated histone H3 [K4], acetylated histone $\mathrm{H} 3$ [K9, 14], and trimethylated histone H3 [K9]. Quantification was performed using qRT-PCR (Sso-Fast EvaGreen) with primers specific to the proposed LXR element sites. The relative amount of immunoprecipitated genomic DNA was normalized to total genomic DNA. Data are represented as arbitrary values using the $\Delta \Delta \mathrm{Ct}$ method. Results are expressed as the mean \pm standard error (SEM). * $=$ Statistically significant. $n=4-6$ (Reprinted from Vo et al. [67], with permission from BioScientifica Ltd.) 


\section{Author's Proof}

9 Maternal Undernutrition and Long-Term Effects on Hepatic Function

augmented expression of hepatic gluconeogenic enzymes (e.g., G6Pase and 11ß-HSD1) contributing to glucose intolerance [67].

MiRs, which consist of short, noncoding RNA molecules of 20-25 nucleotides in length, can also act in an epigenetic manner to regulate gene expression by repressing the translation of proteins or decreasing messenger RNA (mRNA) stability. MPR during pregnancy and lactation has been demonstrated to increase the expression of miR-29a, miR-29b, and miR-29c in the liver by 3 weeks and 4 months of age which silences the expression of Igf-1 and decreases body weight [63]. Interestingly, protein restriction during lactation alone had a greater effect to augment the miR-29 family and suppress Igf-1, while restoration of maternal dietary proteins in MPR offspring at birth prevented miR-29 repression of Igf-1 [63]. In the guinea pig, uterine ligation in pregnancy led to decreases in hepatic miR-146a expression in the 5-month offspring, concomitant with an increase in its target profibrotic gene, SMAD4 [44]. Further studies are warranted to investigate how the expression of miRs in the liver is altered by perinatal undernutrition via direct (i.e., regulation of $5^{\prime}$-UTR of miR promoters) and indirect (i.e., ER stress) mechanisms [75].

\section{Indirect Mechanisms Linking Maternal Undernutrition and Adverse Metabolic Outcomes: The Contribution of Catch-Up Growth}

In several animal models of maternal undernutrition leading to metabolic disease, often the changes in hepatic gene expression do not occur directly at the time of the perinatal insult but manifests later in life $[58,64,72]$. This may be attributed to long-term global changes (e.g., epigenetic mechanisms), initiated by the perinatal environment, which precedes the eventual alterations in gene function. For example, in MPR offspring whereby increases in trimethylation of histone $\mathrm{H} 3$ [lysine 9] silencing the promoter of $C y p 7 a 1$ was present in 3 week and 4 month offspring, alterations in histone methylation were not yet occurring in embryonic life [34]. However, the stage was beginning to be set as MPRmediated decreases in the fetal expression of histone demethylases in the liver were apparent [34].

The more probable reason for indirect effects of a perinatal undernutrition and long-term alterations in hepatic gene expression is rapid postnatal catch-up growth. As previously mentioned, in humans postnatal catch-up growth can accelerate the onset and exacerbate the symptoms of metabolic disease in low birth weight children [25, 29-31]. Given the undernourished neonatal liver undergoes major catch-up growth postpartum, it is quite conceivable that the "stress" of active hepatocyte growth and replication during this period of time may confer detrimental metabolic deficits which only arise after this window of recovery. The leading mechanism likely involved in this rapid growth-triggered process is endoplasmic reticulum (ER) stress.

ER stress occurs when perturbation in the function or homeostasis of the ER leads to luminal accumulation of misfolded or unfolded proteins [64]. Many known triggers of ER stress include impaired disulfide bond formation, compromised $\mathrm{Ca}^{2+}$ homeostasis, low amino acids, hypoxia, decreased $\mathrm{N}$-linked glycosylation, increased lipid load, and greater oxidative stress. In response to ER stress, the unfolded protein response (UPR) tries to restore ER homeostasis by attenuating protein translation (i.e., increased $\mathrm{pEIF} 2 \alpha$ ) while at the same time increasing the expression of chaperone proteins involved in refolding proteins to alleviate the ER. However, if ER stress persists, apoptosis is initiated leading to alterations in gene expression and cell function. In MPR offspring with postnatal catch-up growth (due to restoration of proteins at weaning), the livers at 4 months exhibit ER stress (i.e., increased pEIF2 $\alpha$ ) attributed to impaired insulin sensitivity (e.g., decreased pAkt1[Ser473] despite the fact that the food intake is similar (Fig. 9.2, LP2) [63, 64]. Conversely, if there is no catch-up growth, protein translation is enhanced with higher hepatic insulin sensitivity (Fig. 9.2, LPI) [64]. The low-protein diet itself does not appear to be playing a direct role given alterations in the ER stress pathway were not detected in the fetal liver. Given oxidative stress is present in the undernourished liver, and that the "mismatch" in the nutritional environment likely leads to lipid overload and/or 


\section{Author's Proof}

D.B. Hardy

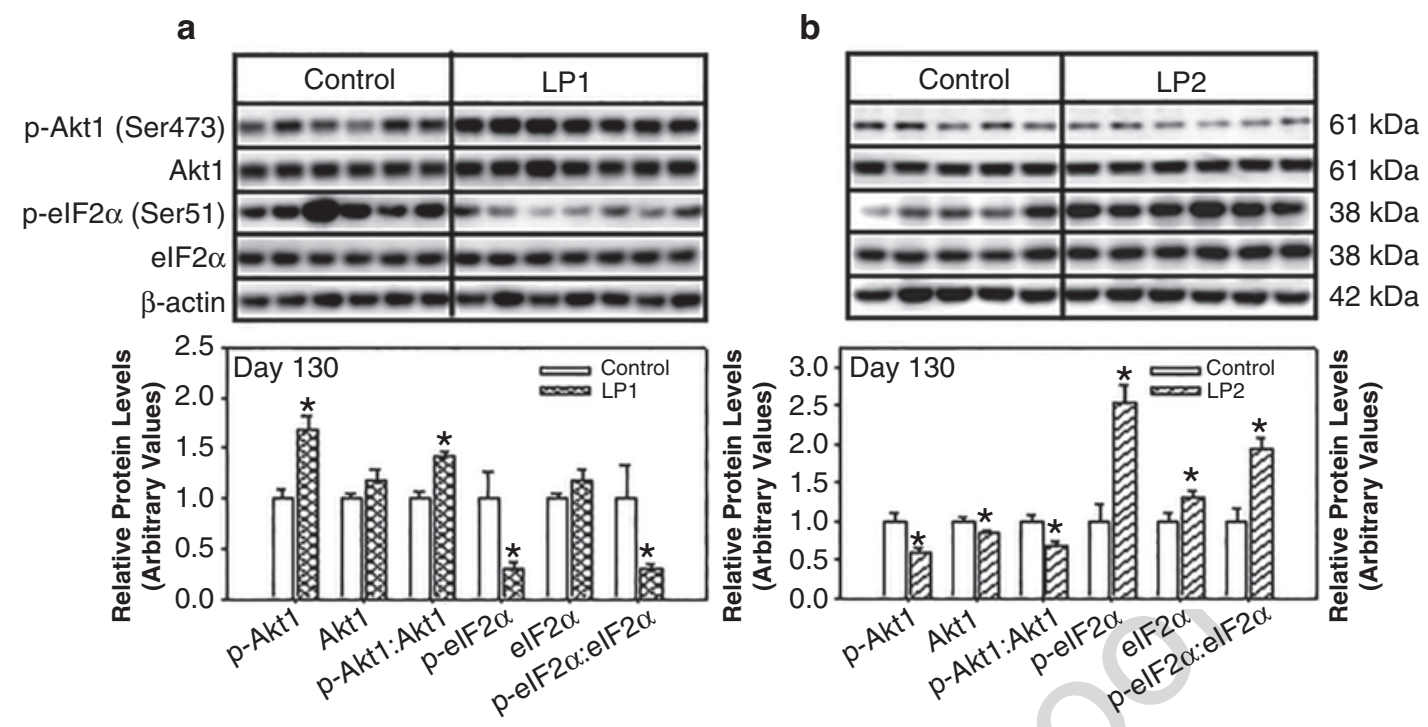

Fig. 9.2 The effect of maternal low-protein dietary regimes on hepatic phosphorylated eIF2 $\alpha$ (Ser51) protein levels at 4 months of age. The effect of (a) LP1 (low protein all life) and (b) LP2 (low-protein pregnancy and lactation) dietary regimes on phosphorylated protein kinase B (Akt1) at serine 473, Akt1, phosphorylated eukaryotic initiation factor $2 \alpha$ $(\mathrm{eIF} 2 \alpha)$ at serine 51, and eIF $2 \alpha$ protein levels in the livers of male offspring at postnatal day 130. Relative p-Akt1 (S473), Akt1, p-eIF2 $\alpha$ (S51), and eIF2 $\alpha$ protein levels were determined using Western blot analysis. Total protein was isolated and p-Akt1 (S473), Akt1, p-eIF2 $\alpha$ (S51), and eIF2 $\alpha$ protein were detected on a Western blot using p-Akt1 (S473), Akt1, p-eIF2 $\alpha$ (S51), and eIF2 $\alpha$ primary antibody. Their protein levels were quantified using densitometry and normalized to that of $\beta$-actin protein levels. Results were expressed as the mean \pm SEM. *, significant difference $(P<0.05) ; n=5-6$ for control and $n=6-7$ for LP1 and LP2 group, where each $\mathrm{n}$ represents a single offspring derived from a different mother (Reprinted from Sohi et al. [64], with permission from Elsevier Ltd.)

impaired disulfide bond formation, it is apparent that these triggers during perinatal life, coupled with postnatal catch-up growth, may initiate the cascade leading to chronic ER stress [35, 47]. It is noteworthy that in a perinatal rat model of nicotine exposure leading to postnatal catch-up growth and dyslipidemia, ER stress was also evident in the adipose tissue of 6-month offspring [76]. Aside from directly influencing hepatic gene expression and function, augmented ER stress in the liver may also alter epigenetic mechanisms such as miRs. For example, activation of ER stress has been demonstrated to induce miR-29a which is known to silence Igf-1 and pAkt-1 (Ser473) [75]. It is noteworthy that miR-29a is increased in 4-month MPR offspring with catch-up growth and ER stress, coupled with decreased Igf-1 an pAkt-1 (Ser473) [63, 64]. An overview of the direct and indirect mechanism involved in the nutritional programming of the perinatal liver is illustrated in Fig. 9.3.

\section{The "Plastic Liver": Intervening in Early Life to Prevent Long-Term Metabolic Dysfunction}

From fetal to neonatal life, the liver undergoes extensive growth, differentiation, and remodeling creating an ideal window for intervention given its plasticity. During fetal life, the liver is considered mainly hematopoietic, while in postnatal life is considered more hepatocyte-like [77]. This may explain why certain perinatal nutritional insults altering postnatal gene expression are differentially altered in fetal life $[67,72]$. By mid-gestation in rodents, the liver bud is formed containing progenitor cells that differentiate into either hepatocytes or ductal cells; however, in the last 3 days of gestation, 


\section{Author's Proof}

9 Maternal Undernutrition and Long-Term Effects on Hepatic Function

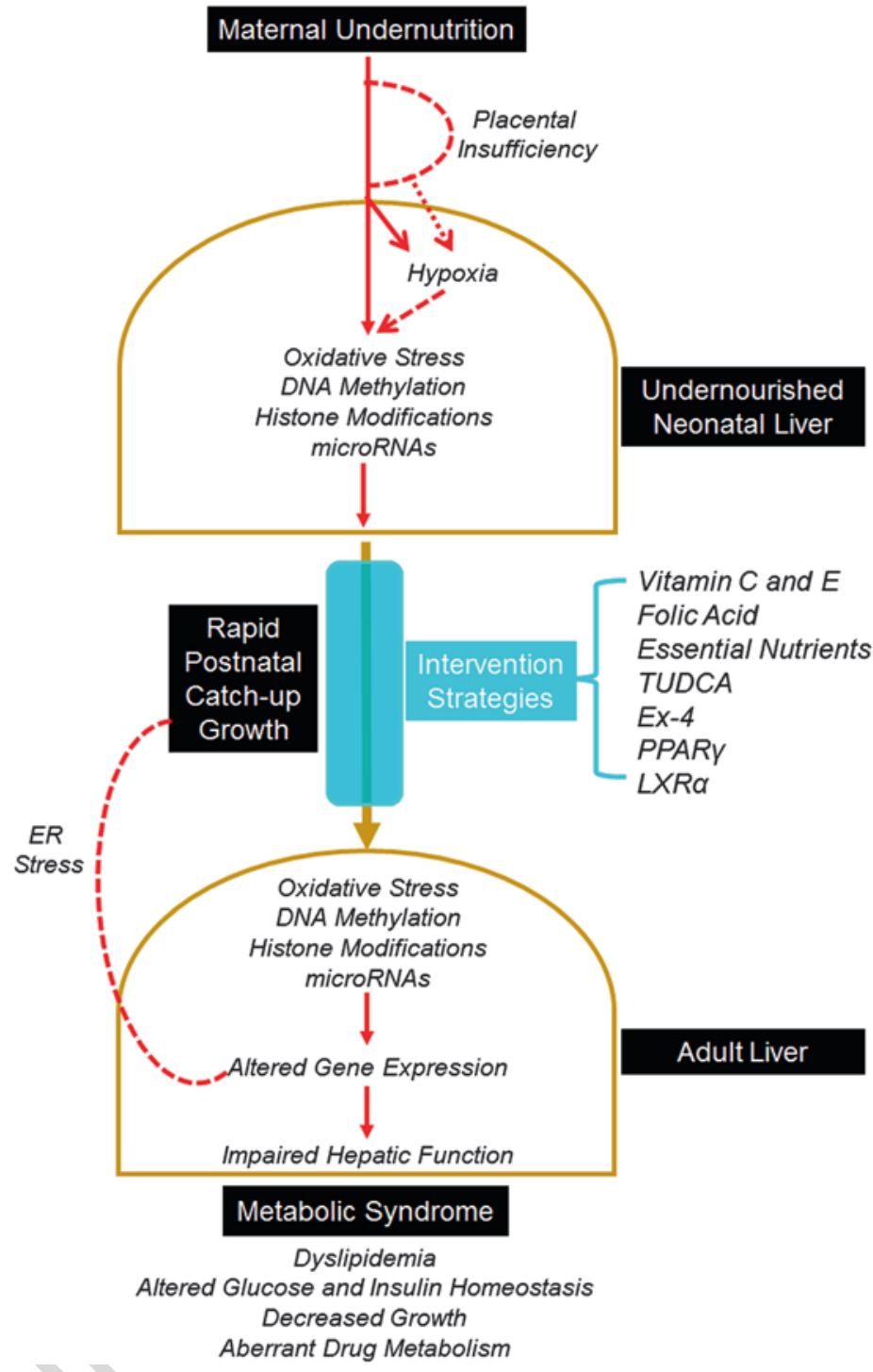

Fig. 9.3 Overview of the direct and indirect mechanisms underlying how undernutrition in utero impairs liver function from neonatal to adult life. Direct pathways altered by maternal undernutrition are indicated by red solid arrows, while indirect pathways affected by placental insufficiency and postnatal catch-up growth are indicated by red dashed arrows. Neonatal intervention strategies are illustrated in cyan arrows

the liver mass triples due to extensive proliferation [78, 79]. After birth in rodents, there is a greater transition from fetal to adult hepatocytes accompanied by high rates of replication, neogenesis, and apoptosis [79]. The human liver develops in a similar pattern, although the majority of liver differentiation occurs in prenatal life [80]. It is estimated that the postnatal rodent liver at 3 weeks is equivalent to the human liver at the third trimester. Regardless of the species, the perinatal liver is undergoing extensive remodeling and is subject to alterations by environmental cues during this period. These cues can consist of alterations in nutrition, hormones/cell signaling, epigenetic forces, and/or by the actions of pharmaceuticals. 


\section{Author's Proof}

From a nutrition standpoint, several studies have investigated the role of vitamins, folic acid, and proteins to reverse the effects of undernutrition on hepatic health. In a maternal diabetes model leading to IUGR and decreased liver weight in Sabra rats, supplementation of vitamins $\mathrm{C}$ and $\mathrm{E}$ in pregnancy prevented decreases in fetal liver weight, but not total bodyweight [81]. The IUGRassociated lipid peroxidation in these fetal livers was also significantly reduced due to maternal vitamin supplementation attributed to increases in superoxide dismutase antioxidant activity [81]. Given its role a methyl donor for DNA methylation, intervention studies with folic acid show promise in reversing some of the epigenetic mechanisms associated with the undernourished liver. Elegant studies by Lillycrop demonstrated that administration of folic acid during MPR pregnancy reversed the decreases in DNA methylation to the promoters of PPAR $\alpha$ and GR and subsequently diminished the MPR increases in their fetal gene expression. But with respect to DNA methylation, the benefits of folic acid appear to be promoter specific given periconceptional intake of folic acid (400 $\mu \mathrm{g} /$ day) led to an increase in DNA methylation of hepatic insulin growth-like factor 2 and, subsequently, low birth weight [82]. As mentioned previously, introduction of a combination of nutrients (i.e., folic acid, vitamin $\mathrm{B}_{12}$ ) to the diet of IUGR offspring has multigenerational effects given the F2 generation did not exhibit impairments in hepatic and lipid homeostasis [48]. The use of the bile acid tauroursodeoxycholic acid (TUDCA) could be considered as a promising safe therapeutic agent in neonatal life given its ability to reduce ER stress (e.g., protein refolding) and consequentially improve liver insulin sensitivity [83]. With regard to protein supplementation, the beneficial effects of restoring maternal proteins also appear to be very promoter specific in the liver. In rats, restoring maternal proteins at birth prevents long-term decreases in hepatic cholesterol metabolism (e.g., Cyp7a1) and Igf-1 but leads to greater expression of genes involved in gluconeogenesis (e.g., G6Pase and 11 $\beta$-HSD1) [34, 63, 67]. These studies illustrate the complexity between the length of the nutritional insult, epigenetics, and catch-up growth on long-term hepatic gene expression.

Hormones and nuclear receptors have promise in reversing the adverse effects of undernutrition on hepatic dysfunction. One of the best examples is with the use of the glucagon-like peptide-1 (Glp-1) analog, exendin-4 (Ex-4). Neonatal administration of Ex-4 to uterine-ligated IUGR offspring prevented the long-term development of hepatic oxidative stress and insulin resistance [47]. It also exerted beneficial effects on the pancreatic $\beta$ cells via increases in the expression of Pdx-1 [84]. Another hormone and antioxidant, melatonin, has been demonstrated in increase umbilical blood flow during gestation in sheep, but it did not rescue growth restriction in undernourished ewes [85]. Targeting nuclear receptors may have a more sustained impact given their widespread roles in influencing endocrine function along with glucose and lipid homeostasis. Female IUGR offspring treated with agonists to the lipid-sensing nuclear receptor PPAR $\gamma$ have long-term insulin-sensitizing effects, although hypoglycemia was also exhibited [86]. Given the role of the liver X receptor (LXR $\alpha)$ in regulating cholesterol, glucose, and fatty acid homeostasis, altering LXR activity in early life could impair several symptoms of the metabolic syndrome. A pilot study using the LXR agonist (GW3695) during neonatal life (PND5-15) in MPR offspring led to decreased total cholesterol levels concomitant with increased LXR $\alpha$ and Cyp7a1 by 3 weeks of age [87]. An overview of the known neonatal interventions is summarized in Fig. 9.3.

Regardless of the success of particular intervention strategies in animal models, caution must be approached in assessing its overall efficacy. The intervention must be examined in the context of the species examined and how the timing of intervention relates to liver development (e.g., plasticity) between species. The impact of the intervention on epigenetic mechanisms must also be considered to determine its sustainability long-term but, more importantly, on the specificity (or lack thereof) to particular target promoters. For the time being, the safer approach may be in general dietary implementation to reduce catch-up growth and the indirect burden it exerts on hepatic development and function. 


\section{Author's Proof}

9 Maternal Undernutrition and Long-Term Effects on Hepatic Function

\section{Conclusion}

In response to maternal undernutrition and placental insufficiency, the fetal liver takes a huge hit with respect to development and growth. Consequentially, the undernourished neonatal liver has the most to gain in postnatal life leading to accelerated catch-up growth. However, both developmental events end up being detrimental to long-term liver function. The present review illustrates the direct epigenetic mechanisms underlying the aberrant expression of hepatic genes in malnourished offspring which persists into adulthood. Hypoxia in the neonatal liver also plays a role in driving some of these epigenetic mechanisms along with increased oxidative stress. With ensuing rapid catch-up growth in postnatal life, this places a burden on the normal growth trajectory of the liver leading to onset of ER stress. This culminates in further metabolic dysfunction such as ER-mediated insulin insensitivity in the liver. In this chapter, nutritional, hormonal, and pharmaceutical interventions early in life are cited which mitigate the effects of undernutrition on hepatic gene expression and function short- and longterm. However, further studies are warranted to address the safety, specificity, and sustainability of these interventions to the whole organism. Until that time, more conventional nutritional steps are necessary to reduce postnatal catch-up growth of IUGR offspring in the hope to reduce global effects (e.g., ER stress) on the recovering liver.

\section{References}

1. Wilson PW, D’Agostino RB, Levy D, Belanger AM, Silbershatz H, Kannel WB. Prediction of coronary heart disease using risk factor categories. Circulation. 1998;97(18):1837-47.

2. Mathieu P, Pibarot P, Despres JP. Metabolic syndrome: the danger signal in atherosclerosis. Vasc Health Risk Manag. 2006;2(3):285-302.

3. Writing Group Members, Lloyd-Jones D, Adams RJ, Brown TM, Carnethon M, Dai S, et al. Heart disease and stroke statistics - 2010 update: a report from the American Heart Association. Circulation. 2010;121(7):e46-215.

4. Lamarche B, Lemieux S, Dagenais GR, Despres JP. Visceral obesity and the risk of ischaemic heart disease: insights from the Quebec Cardiovascular Study. Growth Hormon IGF Res Off J Growth Horm Res Soc Int Res Soc. 1998;8(Suppl B(Journal Article)):1-8.

5. Schocken DD, Benjamin EJ, Fonarow GC, Krumholz HM, Levy D, Mensah GA, et al. Prevention of heart failure: a scientific statement from the American Heart Association Councils on Epidemiology and Prevention, Clinical Cardiology, Cardiovascular Nursing, and High Blood Pressure Research; Quality of Care and Outcomes Research Interdisciplinary Working Group; and Functional Genomics and Translational Biology Interdisciplinary Working Group. Circulation. 2008;117(19):2544-65.

6. Lloyd-Jones D, Adams RJ, Brown TM, Carnethon M, Dai S, De Simone G, et al. Executive summary: heart disease and stroke statistics - 2010 update: a report from the American Heart Association. Circulation. 2010;121(7):948-54.

7. Mehal WZ, Iredale J, Friedman SL. Scraping fibrosis: expressway to the core of fibrosis. Nat Med. 2011;17(5):552-3.

8. Henderson NC, Iredale JP. Liver fibrosis: cellular mechanisms of progression and resolution. Clin Sci Lond Engl 1979. 2007;112(5):265-80.

9. McCullough AJ. The clinical features, diagnosis and natural history of nonalcoholic fatty liver disease. Clin Liver Dis. 2004;8(3):521-33. viii.

10. Ekstedt M, Franzén LE, Mathiesen UL, Thorelius L, Holmqvist M, Bodemar G, et al. Long-term follow-up of patients with NAFLD and elevated liver enzymes. Hepatol Baltim Md. 2006;44(4):865-73.

11. Bhaskar ME. Management of cirrhosis and ascites. N Engl J Med. 2004;351(3):300-1. author reply 300-1.

12. Kohli R, Kirby M, Xanthakos SA, Softic S, Feldstein AE, Saxena V, et al. High-fructose, medium chain trans fat diet induces liver fibrosis and elevates plasma coenzyme Q9 in a novel murine model of obesity and nonalcoholic steatohepatitis. Hepatol Baltim Md. 2010;52(3):934-44.

13. Ishimoto T, Lanaspa MA, Rivard CJ, Roncal-Jimenez CA, Orlicky DJ, Cicerchi C, et al. High-fat and high-sucrose (western) diet induces steatohepatitis that is dependent on fructokinase. Hepatol Baltim Md. 2013;58(5):1632-43.

14. Nordestgaard BG, Benn M, Schnohr P, Tybjaerg-Hansen A. Nonfasting triglycerides and risk of myocardial infarction, ischemic heart disease, and death in men and women. JAMA J Am Med Assoc. 2007;298(3):299-308. 


\section{Author's Proof}

16. Law MR, Wald NJ, Rudnicka AR. Quantifying effect of statins on low density lipoprotein cholesterol, ischaemic heart disease, and stroke: systematic review and meta-analysis. BMJ. 2003;326(7404):1423.

17. Barker DJ. The fetal and infant origins of adult disease. BMJ. 1990;301(6761):1111.

18. Barker DJ, Martyn CN, Osmond C, Hales CN, Fall CH. Growth in utero and serum cholesterol concentrations in adult life. BMJ. 1993;307(6918):1524-7.

19. Valsamakis G, Kanaka-Gantenbein C, Malamitsi-Puchner A, Mastorakos G. Causes of intrauterine growth restriction and the postnatal development of the metabolic syndrome. Ann N Y Acad Sci. 2006;1092:138-47.

20. Neerhof MG. Causes of intrauterine growth restriction. Clin Perinatol. 1995;22(2):375-85.

21. Ravelli GP, Stein ZA, Susser MW. Obesity in young men after famine exposure in utero and early infancy. N Engl J Med. 1976;295(7):349-53.

22. Desai M, Hales CN. Role of fetal and infant growth in programming metabolism in later life. Biol Rev Camb Philos Soc. 1997;72(2):329-48.

23. Hales CN, Barker DJ, Clark PM, Cox LJ, Fall C, Osmond C, et al. Fetal and infant growth and impaired glucose tolerance at age 64. BMJ. 1991;303(6809):1019-22.

24. McCance DR, Pettitt DJ, Hanson RL, Jacobsson LT, Knowler WC, Bennett PH. Birth weight and non-insulin dependent diabetes: thrifty genotype, thrifty phenotype, or surviving small baby genotype? BMJ. 1994;308(6934): 942-5.

25. Finken MJ, Inderson A, Van Montfoort N, Keijzer-Veen MG, van Weert AW, Carfil N, et al. Lipid profile and carotid intima-media thickness in a prospective cohort of very preterm subjects at age 19 years: effects of early growth and current body composition. Pediatr Res. 2006;59(4 Pt 1):604-9.

26. Ravelli AC, van der Meulen JH, Michels RP, Osmond C, Barker DJ, Hales CN, et al. Glucose tolerance in adults after prenatal exposure to famine. Lancet. 1998;351(9097):173-7.

27. Forsdahl A. Living conditions in childhood and subsequent development of risk factors for arteriosclerotic heart disease. The cardiovascular survey in Finnmark 1974-75. J Epidemiol Community Health. 1978;32(1):34-7.

28. Yudkin JS, Stanner S. Prenatal exposure to famine and health in later life. Lancet. 1998;351(9112):1361-2.

29. Yajnik C. Interactions of perturbations in intrauterine growth and growth during childhood on the risk of adult-onset disease. Proc Nutr Soc. 2000;59(2):257-65.

30. Eriksson JG. Early growth, and coronary heart disease and type 2 diabetes: experiences from the Helsinki Birth Cohort studies. Int J Obes 2005. 2006;30(Suppl 4(Journal Article)):S18-22.

31. Martin RM, McCarthy A, Smith GD, Davies DP, Ben-Shlomo Y. Infant nutrition and blood pressure in early adulthood: the Barry Caerphilly growth study. Am J Clin Nutr. 2003;77(6):1489-97.

32. Hales CN, Barker DJ. Type 2 (non-insulin-dependent) diabetes mellitus: the thrifty phenotype hypothesis. Diabetologia. 1992;35(7):595-601.

33. Hales CN, Barker DJ. The thrifty phenotype hypothesis. Br Med Bull. 2001;60(Journal Article):5-20.

34. Sohi G, Marchand K, Revesz A, Arany E, Hardy DB. Maternal protein restriction elevates cholesterol in adult rat offspring due to repressive changes in histone modifications at the cholesterol 7alpha-hydroxylase promoter. Mol Endocrinol Baltim Md. 2011;25(5):785-98.

35. Peterside IE, Selak MA, Simmons RA. Impaired oxidative phosphorylation in hepatic mitochondria in growthretarded rats. Am J Physiol Endocrinol Metab. 2003;285(6):E1258-66.

36. Nevin CMY, Matushewski B, R TRH, Richardson BS. Maternal nutrient restriction (MNR) in guinea pigs leads to fetal growth restricted (FGR) offspring with differential rates of organ catch-up growth. Reprod Sci. 2016; in revision.

37. Deiber M, Chatelain P, Naville D, Putet G, Salle B. Functional hypersomatotropism in small for gestational age (SGA) newborn infants. J Clin Endocrinol Metab. 1989;68(1):232-4.

38. Singhal A, Cole TJ, Fewtrell M, Lucas A. Breastmilk feeding and lipoprotein profile in adolescents born preterm: follow-up of a prospective randomised study. Lancet. 2004;363(9421):1571-8.

39. Jaquet D, Gaboriau A, Czernichow P, Levy-Marchal C. Insulin resistance early in adulthood in subjects born with intrauterine growth retardation. J Clin Endocrinol Metab. 2000;85(4):1401-6.

40. Ross MG, Beall MH. Prediction of preterm birth: nonsonographic cervical methods. Semin Perinatol. 2009;33(5):312-6.

41. Murotsuki J, Challis JR, Han VK, Fraher LJ, Gagnon R. Chronic fetal placental embolization and hypoxemia cause hypertension and myocardial hypertrophy in fetal sheep. Am J Phys. 1997;272(1 Pt 2):R201-7.

42. Ogata ES, Bussey ME, Finley S. Altered gas exchange, limited glucose and branched chain amino acids, and hypoinsulinism retard fetal growth in the rat. Metabolism. 1986;35(10):970-7.

43. Simmons RA, Gounis AS, Bangalore SA, Ogata ES. Intrauterine growth retardation: fetal glucose transport is diminished in lung but spared in brain. Pediatr Res. 1992;31(1):59-63.

44. Sarr O, Blake A, Thompson JA, Zhao L, Rabicki K, Walsh JC, et al. The differential effects of low birth weight and western diet consumption upon early life hepatic fibrosis development in guinea pig. J Physiol. 2015.

45. Lane RH, Kelley DE, Gruetzmacher EM, Devaskar SU. Uteroplacental insufficiency alters hepatic fatty acidmetabolizing enzymes in juvenile and adult rats. Am J Phys Regul Integr Comp Phys. 2001;280(1):R183-90. 


\section{Author's Proof}

9 Maternal Undernutrition and Long-Term Effects on Hepatic Function

46. Simmons RA, Templeton LJ, Gertz SJ. Intrauterine growth retardation leads to the development of type 2 diabetes in the rat. Diabetes. 2001;50(10):2279-86.

47. Raab EL, Vuguin PM, Stoffers DA, Simmons RA. Neonatal exendin-4 treatment reduces oxidative stress and prevents hepatic insulin resistance in intrauterine growth-retarded rats. Am J Phys Regul Integr Comp Phys. 2009;297(6):R1785-94.

48. Goodspeed D, Seferovic MD, Holland W, Mcknight RA, Summers SA, Branch DW, et al. Essential nutrient supplementation prevents heritable metabolic disease in multigenerational intrauterine growth-restricted rats. FASEB J Off Publ Fed Am Soc Exp Biol. 2015;29(3):807-19.

49. Baserga M, Hale MA, McKnight RA, Yu X, Callaway CW, Lane RH. Uteroplacental insufficiency alters hepatic expression, phosphorylation, and activity of the glucocorticoid receptor in fetal IUGR rats. Am J Phys Regul Integr Comp Phys. 2005;289(5):R1348-53.

50. Lane RH, Crawford SE, Flozak AS, Simmons RA. Localization and quantification of glucose transporters in liver of growth-retarded fetal and neonatal rats. Am J Phys. 1999;276(1 Pt 1):E135-42.

51. Lane RH, MacLennan NK, Hsu JL, Janke SM, Pham TD. Increased hepatic peroxisome proliferator-activated receptor-gamma coactivator-1 gene expression in a rat model of intrauterine growth retardation and subsequent insulin resistance. Endocrinology. 2002;143(7):2486-90.

52. Fu Q, Yu X, Callaway CW, Lane RH, McKnight RA. Epigenetics: intrauterine growth retardation (IUGR) modifies the histone code along the rat hepatic IGF-1 gene. FASEB J Off Publ Fed Am Soc Exp Biol. 2009;23(8):2438-49.

53. Zinkhan EK, Chin JR, Zalla JM, Yu B, Numpang B, Yu X, et al. Combination of intrauterine growth restriction and a high-fat diet impairs cholesterol elimination in rats. Pediatr Res. 2014;76(5):432-40.

54. Zhang J, Lewis RM, Wang C, Hales N, Byrne CD. Maternal dietary iron restriction modulates hepatic lipid metabolism in the fetuses. Am J Physiol Integr Comp Physiol. 2005;288(1):R104-11.

55. Elias AA, Ghaly A, Matushewski B, Regnault TRH, Richardson BS. Maternal nutrient restriction in guinea pigs as an animal model for inducing fetal growth restriction. Reprod Sci Thousand Oaks Calif. 2015.

56. Lumey LH. Compensatory placental growth after restricted maternal nutrition in early pregnancy. Placenta. 1998;19(1):105-11.

57. Sohlström A, Katsman A, Kind KL, Roberts CT, Owens PC, Robinson JS, et al. Food restriction alters pregnancyassociated changes in IGF and IGFBP in the guinea pig. Am J Phys. 1998;274(3 Pt 1):E410-6.

58. Tosh DN, Fu Q, Callaway CW, McKnight RA, McMillen IC, Ross MG, et al. Epigenetics of programmed obesity: alteration in IUGR rat hepatic IGF1 mRNA expression and histone structure in rapid vs. delayed postnatal catch-up growth. Am J Physiol Gastrointest Liver Physiol. 2010;299(5):G1023-9.

59. Nijland MJ, Mitsuya K, Li C, Ford S, McDonald TJ, Nathanielsz PW, et al. Epigenetic modification of fetal baboon hepatic phosphoenolpyruvate carboxykinase following exposure to moderately reduced nutrient availability. J Physiol. 2010;588(Pt 8):1349-59.

60. George LA, Zhang L, Tuersunjiang N, Ma Y, Long NM, Uthlaut AB, et al. Early maternal undernutrition programs increased feed intake, altered glucose metabolism and insulin secretion, and liver function in aged female offspring. Am J Phys Regul Integr Comp Phys. 2012;302(7):R795-804.

61. Petry CJ, OzanneSE, Hales CN.Programming of intermediary metabolism. MolCellEndocrinol.2001;185(1-2):81-91.

62. Crosby WM. Studies in fetal malnutrition. Am J Dis Child 1960. 1991;145(8):871-6.

63. Sohi G, Revesz A, Ramkumar J, Hardy DB. Higher hepatic miR-29 expression in undernourished male rats during the postnatal period targets the long-term repression of IGF-1. Endocrinology. 2015;156(9):3069-76.

64. Sohi G, Revesz A, Hardy DB. Nutritional mismatch in postnatal life of low birth weight rat offspring leads to increased phosphorylation of hepatic eukaryotic initiation factor $2 \alpha$ in adulthood. Metabolism. 2013;62(10):1367-74.

65. Guan H, Arany E, van Beek JP, Chamson-Reig A, Thyssen S, Hill DJ, et al. Adipose tissue gene expression profiling reveals distinct molecular pathways that define visceral adiposity in offspring of maternal protein-restricted rats. Am J Physiol Metab. 2005;288(4):E663-73.

66. Petrik J, Reusens B, Arany E, Remacle C, Coelho C, Hoet JJ, et al. A low protein diet alters the balance of islet cell replication and apoptosis in the fetal and neonatal rat and is associated with a reduced pancreatic expression of insulin-like growth factor-II. Endocrinology. 1999;140(10):4861-73.

67. Vo T, Revesz A, Ma N, Hardy DB. Maternal protein restriction leads to enhanced hepatic gluconeogenic gene expression in adult male rat offspring due to impaired expression of the liver x receptor. J Endocrinol. 2013;218(Journal Article):85-97.

68. Chamson-Reig A, Thyssen SM, Hill DJ, Arany E. Exposure of the pregnant rat to low protein diet causes impaired glucose homeostasis in the young adult offspring by different mechanisms in males and females. Exp Biol Med Maywood NJ. 2009;234(12):1425-36.

69. Petry CJ, Ozanne SE, Wang CL, Hales CN. Early protein restriction and obesity independently induce hypertension in 1-year-old rats. Clin Sci Lond Engl 1979. 1997;93(2):147-52.

70. Burns SP, Desai M, Cohen RD, Hales CN, Iles RA, Germain JP, et al. Gluconeogenesis, glucose handling, and structural changes in livers of the adult offspring of rats partially deprived of protein during pregnancy and lactation. J Clin Invest. 1997;100(7):1768-74. 


\section{Author's Proof}

71. Ozanne SE, Smith GD, Tikerpae J, Hales CN. Altered regulation of hepatic glucose output in the male offspring of protein-malnourished rat dams. Am J Phys. 1996;270(4 Pt 1):E559-64.

72. Sohi G, Barry EJ, Velenosi TJ, Urquhart BL, Hardy DB. Protein restoration in low-birth-weight rat offspring derived from maternal low-protein diet leads to elevated hepatic CYP3A and CYP2C11 activity in adulthood. Drug Metab Dispos Biol Fate Chem. 2014;42(2):221-8.

73. Elias AA, M B, Zhao L, N K, Regnault TRH, R BS. Maternal nutrient restriction in guinea pigs leads to fetal growth restriction with evidence for chronic hypoxia. Am J Physiol. in revision (n.d).

74. Fu Q, McKnight RA, Callaway CW, Yu X, Lane RH, Majnik AV. Intrauterine growth restriction disrupts developmental epigenetics around distal growth hormone response elements on the rat hepatic IGF-1 gene. FASEB J Off Publ Fed Am Soc Exp Biol. 2015;29(4):1176-84.

75. Nolan K, Mitchem MR, Jimenez-Mateos EM, Henshall DC, Concannon CG, Prehn JH. Increased expression of microRNA-29a in ALS mice: functional analysis of its inhibition. J Mol Neurosci MN. 2014;53(2):231-41.

76. Barra NG, VanDuzer T, Holloway AC, Hardy DB. Maternal nicotine exposure (MNE) leads to decreased visceral adipocyte size associated with endoplasmic reticulum (ER) stress in 26 week old rat offspring. Reprod Sci. 2016; accepted.

77. Gualdi R, Bossard P, Zheng M, Hamada Y, Coleman JR, Zaret KS. Hepatic specification of the gut endoderm in vitro: cell signaling and transcriptional control. Genes Dev. 1996;10(13):1670-82.

78. Cascio S, Zaret KS. Hepatocyte differentiation initiates during endodermal-mesenchymal interactions prior to liver formation. Dev Camb Engl. 1991;113(1):217-25.

79. Greengard O, Federman M, Knox WE. Cytomorphometry of developing rat liver and its application to enzymic differentiation. J Cell Biol. 1972;52(2):261-72.

80. Kung JWC, Currie IS, Forbes SJ, Ross JA. Liver development, regeneration, and carcinogenesis. J Biomed Biotechnol. 2010;2010:984248.

81. Ornoy A, Tsadok MA, Yaffe P, Zangen SW. The Cohen diabetic rat as a model for fetal growth restriction: vitamins $\mathrm{C}$ and $\mathrm{E}$ reduce fetal oxidative stress but do not restore normal growth. Reprod Toxicol Elmsford N. 2009;28(4):521-9.

82. Steegers-Theunissen RP, Obermann-Borst SA, Kremer D, Lindemans J, Siebel C, Steegers EA, et al. Periconceptional maternal folic acid use of 400 microg per day is related to increased methylation of the IGF2 gene in the very young child. PLoS One. 2009;4(11):e7845.

83. Kars M, Yang L, Gregor MF, Mohammed BS, Pietka TA, Finck BN, et al. Tauroursodeoxycholic acid may improve liver and muscle but not adipose tissue insulin sensitivity in obese men and women. Diabetes. 2010;59(8):1899-905.

84. Pinney SE, Jaeckle Santos LJ, Han Y, Stoffers DA, Simmons RA. Exendin-4 increases histone acetylase activity and reverses epigenetic modifications that silence $\mathrm{Pdx} 1$ in the intrauterine growth retarded rat. Diabetologia. 2011;54(10):2606-14.

85. Lemley CO, Meyer AM, Camacho LE, Neville TL, Newman DJ, Caton JS, et al. Melatonin supplementation alters uteroplacental hemodynamics and fetal development in an ovine model of intrauterine growth restriction. Am J Physiol Integr Comp Physiol. 2012;302(4):R454-67.

86. Garg M, Thamotharan M, Pan G, Lee PW, Devaskar SU. Early exposure of the pregestational intrauterine and postnatal growth-restricted female offspring to a peroxisome proliferator-activated receptor-\{gamma $\}$ agonist. Am J Physiol Metab. 2010;298(3):E489-98.

87. Sohi G, Revesz A, Arany E, Hardy DB. The liver X receptor mediates the impaired cholesterol metabolism exhibited in the offspring of maternal protein restricted rats. Reprod Sci. 2011;18(4):F163. 